\title{
Hypertension and blood pressure among meat eaters, fish eaters, vegetarians and vegans in $\mathrm{EPIC}-\mathrm{Oxford}$
}

\author{
Paul N Appleby*, Gwyneth K Davey and Timothy J Key \\ Cancer Research UK, Epidemiology Unit, University of Oxford, Gibson Building, The Radcliffe Infirmary, \\ Oxford OX2 6HE, UK
}

Submitted 16 November 2001: Accepted 22 January 2002

\begin{abstract}
Objective: To compare the prevalence of self-reported hypertension and mean systolic and diastolic blood pressures in four diet groups (meat eaters, fish eaters, vegetarians and vegans) and to investigate dietary and other lifestyle factors that might account for any differences observed between the groups.

Design: Analysis of cross-sectional data from participants in the Oxford cohort of the European Prospective Investigation into Cancer and Nutrition (EPIC-Oxford).

Setting: United Kingdom.

Subjects: Eleven thousand and four British men and women aged 20-78 years at blood pressure measurement.

Results: The age-adjusted prevalence of self-reported hypertension was significantly different between the four diet groups, ranging from $15.0 \%$ in male meat eaters to $5.8 \%$ in male vegans, and from $12.1 \%$ in female meat eaters to $7.7 \%$ in female vegans, with fish eaters and vegetarians having similar and intermediate prevalences. Mean systolic and diastolic blood pressures were significantly different between the four diet groups, with meat eaters having the highest values and vegans the lowest values. The differences in age-adjusted mean blood pressure between meat eaters and vegans among participants with no self-reported hypertension were 4.2 and $2.6 \mathrm{mmHg}$ systolic and 2.8 and $1.7 \mathrm{mmHg}$ diastolic for men and women, respectively. Much of the variation was attributable to differences in body mass index between the diet groups.

Conclusions: Non-meat eaters, especially vegans, have a lower prevalence of hypertension and lower systolic and diastolic blood pressures than meat eaters, largely because of differences in body mass index.
\end{abstract}

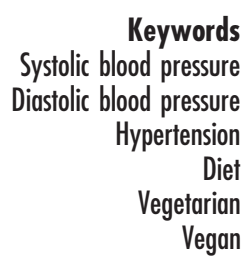

Blood pressure is linearly related to mortality from coronary heart disease ${ }^{1,2}$, and a $5 \mathrm{mmHg}$ increase in usual diastolic blood pressure has been estimated to increase stroke and coronary heart disease risk by $34 \%$ and $21 \%$, respectively ${ }^{3}$. The main diet-related determinants of hypertension are obesity, high intakes of alcohol and sodium, and a low potassium intake ${ }^{4,5}$. Limiting dietary sodium and use of the Dietary Approaches to Stop Hypertension (DASH) diet have been shown to be effective in reducing blood pressure in both normotensive and hypertensive individuals ${ }^{6}$. The DASH diet is rich in vegetables, fruits and low-fat dairy foods, and several studies have found that vegetarians, who might be expected to have a diet similar to this, have lower blood pressure than non-vegetarians ${ }^{7-10}$.

In this study we compare the prevalence of selfreported hypertension and mean systolic and diastolic blood pressures in men and women in four diet groups (meat eaters, fish eaters, vegetarians and vegans) using data from participants in the Oxford cohort of the
European Prospective Investigation into Cancer and Nutrition (EPIC-Oxford). We also attempt to identify diet and lifestyle factors responsible for differences in blood pressure between the diet groups.

\section{Subjects and methods}

Between 1993 and 1999, 57500 British men and women from throughout the UK were recruited into the EPICOxford cohort. Two methods of recruitment were used: general practice (GP) recruitment and postal recruitment. The aim of the GP recruitment was to recruit members of the general population via GP surgeries in Greater Manchester, Oxfordshire and Buckinghamshire. In contrast, the postal method of recruitment was designed so as to recruit as many vegetarians as possible through targeted mailing of vegetarian and vegan societies, health/dietinterest magazines and health food shops.

At recruitment, all participants completed a detailed lifestyle questionnaire, including a semi-quantitative food- 
frequency questionnaire (FFQ) consisting of 130 questions (each with nine possible response categories) relating to the participant's usual diet over the previous year. Data from the FFQ were used to estimate intakes of alcohol, food energy and selected nutrients using Fortran computer programs and nutrient data from McCance and Widdowson's The Composition of Foods and its supplements ${ }^{11-20}$. In addition to alcohol and energy intake, 10 nutrients were selected as being likely to influence blood pressure: protein, carbohydrate, total fat, saturated fat, polyunsaturated fat, non-starch polysaccharide (NSP), sodium, potassium, calcium and magnesium. Intakes of protein, carbohydrate, total fat, saturated fat and polyunsaturated fat were expressed in relative terms as percentages of energy intake, and the intakes of saturated fat and polyunsaturated fat were used to derive the polyunsaturated to saturated fat $(\mathrm{P} / \mathrm{S})$ ratio. Assessment of nutrient intake using the FFQ has been validated previously ${ }^{21}$.

Separately from the FFQ, participants were also asked the following questions: Do you eat any meat?, Do you eat any fish?, Do you eat any dairy products? and Do you eat any eggs? Based on the answers to these questions participants were allocated to one of four diet groups: meat eaters, fish eaters (who ate fish but not meat), vegetarians (who ate neither meat nor fish but did eat dairy products and/or eggs) and vegans (who did not eat any meat, fish, eggs or dairy products). The lifestyle questionnaire also asked participants to record their date of birth, current height and weight, use of salt in cooking and at the table, level of physical activity at work, whether they practised any vigorous exercise during their leisure time, and whether they were currently receiving long-term treatment for any illness or condition. Women were asked to record their parity and whether they were currently taking or had ever taken oral contraceptives (OC) or hormone replacement therapy (HRT). All participants were asked whether they had modified their diet over the past year owing to high blood pressure or had been told by a doctor that they had high blood pressure. Answers to these two questions were combined to determine the percentage of participants with self-reported hypertension. Self-reported height and weight were used to calculate the participant's body mass index (BMI) as their weight in kilograms divided by the square of their height in metres. (Measured heights and weights were available for about 5000 participants, and a previous study showed good agreement with their self-reported values ${ }^{22}$.)

All participants were asked if they would be willing to provide a blood sample and to have their blood pressure measured at their general practice, although the study design only allowed blood samples to be taken from about one-third of participants. The health professional responsible for taking the blood sample was asked to take the participant's blood pressure first, and to record the date and time, how many cigarettes the participant had smoked in the previous 24 hours, and details of any medicines or nutritional supplements they had taken on that day or the previous day. Measurements of systolic blood pressure (SBP) and diastolic blood pressure (DBP) were obtained from about 19500 participants, of whom 7500 were GPrecruited and 12000 had been recruited by post. Because of the possibility of systematic differences in blood pressure measurement arising from the different modes of recruitment, and because almost all of the vegetarians and vegans were recruited by post, it was decided to exclude data for the GP-recruited participants from this analysis. No standard method of blood pressure measurement was specified for the participants recruited by post and only single measurements were taken.

Participants were excluded from the analysis if any of the following conditions applied:

- they were recruited through a general practice ( $n=7421$ participants excluded);

- the date of their blood pressure measurement was unknown or incomplete or they were aged 80 years or above at the time $(n=170)$;

- either the SBP or the DBP measurement was missing or the values were illogical (DBP greater than SBP, $n=189)$;

- their BMI was under $15 \mathrm{~kg} \mathrm{~m}^{-2}$ or over $60 \mathrm{~kg} \mathrm{~m}^{-2}$ ( $n=$ 472); and

- their diet group was unknown, or their nutrient data were deemed unreliable (more than 20\% of the food frequency questions unanswered, or an estimated daily energy intake outside the range 800-4000 kcal for men or 500-3500 kcal for women, $n=195$ ).

After these exclusions data were available for 2351 men (996 meat eaters, 297 fish eaters, 786 vegetarians, 272 vegans) and 8653 women (3741 meat eaters, 1431 fish eaters, 3014 vegetarians, 467 vegans), reflecting the preponderance of women in this cohort.

Data were analysed separately for men and women. Participants were categorised into one of 12 five-year age groups according to their age at blood pressure measurement $(20-24,25-29, \ldots, 75-79$ years), sexspecific fifths of BMI and sex-specific thirds of each nutrient. Alcohol intake was categorised as <1, 1-9, 1019 or $20+\mathrm{g}$ of ethanol per day. Use of salt in cooking and at the table were each categorised as 'rarely or never', 'sometimes' or 'usually or always'. Physical activity level at work was categorised as 'not working', 'sedentary' or 'active' (standing or manual workers). Parity in women was categorised as none, 1-2 or 3 or more children; hormone exposure was categorised as 'never', 'former' or 'current'; and all other factors were categorised as simple yes/no variables.

Hypertension presents a problem when comparing blood pressure measurements because the use of drugs or diet to control the disease may make the observations unreliable. For example, anti-hypertensive drugs would be expected to reduce blood pressure, so that recorded 
blood pressure measurements would be lower than their 'true' value for a person with hypertension. Also, some of the participants with hypertension reported having changed their diet as a consequence of the disease. Therefore, the analysis of blood pressure measurements was restricted to participants with no self-reported hypertension.

The prevalence of self-reported hypertension by diet group, both unadjusted and adjusted for age, and further adjusted for BMI, was calculated for each sex. Chi-square tests were used to assess the statistical significance of differences in prevalence between the diet groups. Mean age-adjusted SBP and DBP by sex among participants with no self-reported hypertension were calculated for diet group and other factors of interest. F-tests were used to assess the statistical significance of the heterogeneity in mean blood pressures across categories. Analysis of variance was used to examine the extent to which differences in age-adjusted blood pressure between the diet groups could be explained by differences in BMI, nutrient intake and other lifestyle factors. For the multivariable analyses an 'unknown' category was added to each factor where necessary so as to include all available observations in the analyses. (For most factors no more than $2 \%$ of participants were classified as being 'unknown', and none of the factors with a higher percentage of 'unknowns' were included in the multivariable analyses. Therefore, observations with 'unknown' values for one or more factors were unlikely to have a major effect on the results.) Reductions in the range of adjusted mean blood pressures across the diet groups (defined as the difference between the highest and the lowest mean blood pressure) were used to quantify the extent to which the various factors accounted for the ageadjusted differences in blood pressure. Statistical analyses were performed using the Stata statistical package ${ }^{23}$.

\section{Results}

Baseline characteristics of the participants by sex and diet group are shown in Table 1. Age at blood pressure measurement ranged from 20 to 78 years with a median of 48 years in men and 46 years in women. There were considerable differences in age between the diet groups for both men and women: median age was progressively lower from the meat eaters to the vegans. These age differences undoubtedly account for some of the other differences in baseline characteristics between the diet groups. BMI was higher in the meat eaters than the vegans, with the fish eaters and vegetarians having similar and intermediate values. A higher proportion of vegan men and women were essentially teetotal (alcohol intake $<1$ g day $^{-1}$ ) than any of the other diet groups, with a correspondingly lower proportion consuming 20 or more grams of alcohol daily. Meat eaters had the highest mean energy intake, and consumed relatively more protein, fat and saturated fat, and relatively less carbohydrate and polyunsaturated fat, than the other diet groups. Vegans consumed much less saturated fat and calcium, had a much higher $\mathrm{P} / \mathrm{S}$ ratio compared with the other diet groups, and also had the highest intakes of NSP and magnesium, but the lowest intakes of sodium from food. Meat eaters were the most likely, and vegans the least likely, to use salt in cooking 'usually or always', and there was a similar pattern for use of salt at the table. A high percentage of participants reported exercising vigorously on a regular basis, with vegans the most active. Vegan women were most likely to be childless and least likely to be taking either oral contraceptives or HRT at recruitment. Meat eaters were the most likely to have taken medication (including prescription medicines, over-the-counter medicines and nutritional supplements) immediately prior to blood pressure measurement and most likely to have been receiving long-term treatment for illness.

Self-reported hypertension was most common among meat eaters and least common among vegans (Table 1). These differences remained after adjusting for age: the adjusted prevalence for meat eaters, fish eaters, vegetarians and vegans, respectively, was 15.0\%, 9.8\%, 9.8\% and $5.8 \%$ for men, and $12.1 \%, 9.6 \%, 8.9 \%$ and $7.7 \%$ for women (each $P<0.0005$ ). The same pattern remained after further adjustment for BMI, although the differences in the prevalence of hypertension between the diet groups were smaller and of reduced statistical significance ( $P=0.01$ for men, $P=0.07$ for women). Adjusted for age and BMI, the prevalence of self-reported hypertension for meat eaters, fish eaters, vegetarians and vegans, respectively, was $12.9 \%, 9.3 \%, 9.5 \%$ and $6.1 \%$ for men, and $10.6 \%, 9.7 \%, 8.7 \%$ and $8.3 \%$ for women.

Blood pressures were compared in 1790 men (699 meat eaters, 233 fish eaters, 628 vegetarians, 230 vegans) and 6873 women (2825 meat eaters, 1171 fish eaters, 2495 vegetarians, 382 vegans) with no self-reported hypertension. BMI was strongly positively associated with blood pressure in both sexes (each $P<0.0001$ ), with a clear gradient of increasing age-adjusted blood pressure with increasing fifth of BMI (Table 2).

There were highly significant differences in ageadjusted SBP and DBP between the diet groups for both men and women (each $P<0.005$ ). In each case, meat eaters had the highest and vegans the lowest adjusted mean values (Table 3). The differences in the age-adjusted mean values between meat eaters and vegans were $4.2 \mathrm{mmHg}$ and $2.6 \mathrm{mmHg} \mathrm{SBP}$, and $2.8 \mathrm{mmHg}$ and $1.7 \mathrm{mmHg}$ DBP, for men and women respectively.

Mean values of SBP and DBP in men and women by alcohol intake, thirds of nutrient intake and other lifestyle factors, each adjusted for age and BMI, are shown in the Appendix. Alcohol intake was positively associated with blood pressure in men, but there was no relationship between blood pressure and alcohol intake in women. Energy intake was positively associated with blood 


\begin{tabular}{|c|c|c|c|c|c|c|c|c|}
\hline \multirow[b]{2}{*}{ Characteristic } & \multicolumn{4}{|c|}{ Men } & \multicolumn{4}{|c|}{ Women } \\
\hline & Meat eaters & Fish eaters & Vegetarians & Vegans & Meat eaters & Fish eaters & Vegetarians & Vegans \\
\hline Number & 996 & 297 & 786 & 272 & 3741 & 1431 & 3014 & 467 \\
\hline Median age at BP measurement (years) & 54 & 49 & 45 & 40 & 51 & 44 & 41 & 37 \\
\hline \multirow{2}{*}{\multicolumn{9}{|c|}{ Alcohol intake (g ethanol day $\left.{ }^{-1}\right)$}} \\
\hline & & & & & & & & \\
\hline$<1$ & $112(11.2)$ & $47(15.8)$ & $154(19.6)$ & $89(32.7)$ & $758(20.3)$ & $267(18.7)$ & $677(22.5)$ & $156(33.4)$ \\
\hline $1-9$ & $408(41.0)$ & $123(41.4)$ & $302(38.4)$ & $97(35.7)$ & $2026(54.2)$ & $748(52.3)$ & $1563(51.9)$ & $223(47.8)$ \\
\hline $10-19$ & $253(25.4)$ & $61(20.5)$ & $161(20.5)$ & $42(15.4)$ & $687(18.4)$ & $283(19.8)$ & $547(18.1)$ & $63(13.5)$ \\
\hline $20+$ & $223(22.4)$ & $66(22.2)$ & $169(21.5)$ & 44 (16.2) & $270(7.2)$ & $133(9.3)$ & $227(7.5)$ & $25(5.4)$ \\
\hline \multicolumn{9}{|l|}{ Mean daily nutrient intakes } \\
\hline Energy $(\mathrm{kJ})$ & 9119 & 9077 & 8909 & 8058 & 8005 & 7897 & 7705 & 7123 \\
\hline Protein (\% energy) & 16.1 & 14.1 & 13.1 & 12.8 & 17.4 & 14.9 & 13.9 & 13.4 \\
\hline Carbohydrate (\% energy) & 47.6 & 50.7 & 51.7 & 54.7 & 49.0 & 51.5 & 53.0 & 55.5 \\
\hline Total fat (\% energy) & 31.5 & 31.1 & 30.9 & 28.7 & 31.1 & 30.6 & 30.4 & 28.7 \\
\hline Saturated fat (\% energy) & 10.4 & 9.1 & 9.1 & 4.9 & 10.0 & 9.2 & 9.2 & 5.2 \\
\hline Polyunsaturated fat (\% energy) & 5.2 & 5.9 & 5.8 & 7.8 & 5.2 & 5.6 & 5.4 & 7.6 \\
\hline $\mathrm{P} / \mathrm{S}$ ratio & 0.56 & 0.72 & 0.71 & 1.65 & 0.57 & 0.67 & 0.66 & 1.53 \\
\hline NSP $(g)$ & 19.9 & 24.0 & 24.0 & 28.2 & 20.2 & 22.7 & 22.9 & 26.5 \\
\hline Sodium (from food only; mg) & 2986 & 3028 & 2979 & 2792 & 2713 & 2680 & 2632 & 2539 \\
\hline Potassium (mg) & 4033 & 4085 & 3972 & 4061 & 3927 & 3881 & 3773 & 3836 \\
\hline Calcium (mg) & 1064 & 1114 & 1091 & 589 & 998 & 1037 & 1021 & 580 \\
\hline Magnesium (mg) & 379 & 416 & 411 & 444 & 355 & 371 & 368 & 397 \\
\hline \multicolumn{9}{|l|}{ Salt added while cooking ${ }^{\star}$} \\
\hline Rarely or never & $338(34.0)$ & $133(44.9)$ & $400(51.0)$ & $174(64.0)$ & $1428(38.3)$ & $712(49.8)$ & $1581(52.5)$ & $281(60.3)$ \\
\hline Sometimes & $192(19.3)$ & $68(23.0)$ & $140(17.9)$ & 45 (16.5) & $613(16.4)$ & $281(19.7)$ & $559(18.6)$ & 78 (16.7) \\
\hline Usually or always & $465(46.7)$ & $95(32.1)$ & $244(31.1)$ & 53 (19.5) & $1691(45.3)$ & $436(30.5)$ & $871(28.9)$ & $107(23.0)$ \\
\hline \multicolumn{9}{|l|}{ Salt added at the table* } \\
\hline Rarely or never & 507 (50.9) & $196(66.0)$ & $482(61.3)$ & $194(71.9)$ & $2270(60.9)$ & $916(64.2)$ & $1945(64.7)$ & $303(65.2)$ \\
\hline Sometimes & $220(22.1)$ & $56(18.9)$ & $150(19.1)$ & $43(15.9)$ & $789(21.2)$ & $289(20.3)$ & $580(19.3)$ & $85(18.3)$ \\
\hline Usually or always & $269(27.0)$ & $45(15.2)$ & $154(19.6)$ & 33 (12.2) & $671(18.0)$ & $222(15.6)$ & $482(16.0)$ & $77(16.6)$ \\
\hline \multicolumn{9}{|l|}{ Physical activity at work* } \\
\hline Not working & 419 (42.5) & $97(33.3)$ & $205(26.6)$ & $104(39.0)$ & $1566(42.9)$ & $446(31.8)$ & $891(30.2)$ & $180(39.4)$ \\
\hline Sedentary & $326(33.1)$ & $111(38.1)$ & $342(44.4)$ & $75(28.1)$ & $1061(29.0)$ & $490(35.0)$ & $1068(36.1)$ & $152(33.3)$ \\
\hline Active & $241(24.4)$ & $83(28.5)$ & $223(29.0)$ & $88(33.0)$ & $1027(28.1)$ & 466 (33.2) & $996(33.7)$ & $125(27.4)$ \\
\hline \multirow{2}{*}{\multicolumn{9}{|c|}{ Parity* ${ }^{*}$ vigur exercise }} \\
\hline & & & & & & & & \\
\hline None & - & - & - & - & $884(23.6)$ & $510(35.7)$ & $1382(45.9)$ & $282(60.5)$ \\
\hline $1-2$ & - & - & - & - & $1906(51.0)$ & $652(45.6)$ & 1198 (39.8) & $130(27.9)$ \\
\hline 3 or more & - & - & - & _- & $950(25.4)$ & $268(18.7)$ & $428(14.2)$ & $54(11.6)$ \\
\hline \multicolumn{9}{|l|}{ Hormone exposure ${ }^{\star}$} \\
\hline Never & - & - & - & - & $853(23.3)$ & $251(17.8)$ & $564(19.0)$ & $110(24.1)$ \\
\hline Former & - & - & - & - & $1952(53.3)$ & $870(61.6)$ & $1722(58.1)$ & $275(60.2)$ \\
\hline Current & - & - & - & - & $860(23.5)$ & $291(20.6)$ & $680(22.9)$ & $72(15.8)$ \\
\hline Smoked cigarettes in $24 \mathrm{~h}$ prior to BP measurement ${ }^{\star}$ & $64(6.5)$ & $15(5.1)$ & $37(4.8)$ & $19(7.0)$ & $256(6.9)$ & $83(5.9)$ & $217(7.3)$ & $38(8.2)$ \\
\hline Took medication $\ddagger$ on day of or day before BP measurement ${ }^{\star}$ & $516(56.5)$ & $143(51.6)$ & 347 (47.3) & 89 (41.2) & 2331 (72.3) & $834(68.0)$ & $1686(64.2)$ & $203(56.7)$ \\
\hline Receiving long-term treatment for any illness or condition* ${ }^{*}$ & $351(35.7)$ & $68(23.3)$ & $185(23.6)$ & $52(19.1)$ & $1365(36.8)$ & $397(28.1)$ & $758(25.4)$ & $96(20.7)$ \\
\hline Self-reported hypertension $\S^{*}$ & $182(20.7)$ & $32(12.1)$ & $68(9.8)$ & $12(5.0)$ & $557(16.5)$ & $140(10.7)$ & $233(8.5)$ & $28(6.8)$ \\
\hline
\end{tabular}


Table 2 Age-adjusted mean (95\% confidence interval) systolic and diastolic blood pressures in men and women with no self-reported hypertension by body mass index

\begin{tabular}{|c|c|c|c|c|}
\hline \multirow[b]{2}{*}{ Fifth of body mass index } & \multicolumn{2}{|c|}{ Systolic blood pressure $(\mathrm{mmHg})$} & \multicolumn{2}{|c|}{ Diastolic blood pressure $(\mathrm{mmHg})$} \\
\hline & Men & Women & Men & Women \\
\hline 1 (lowest) & $120.2(118.8-121.7)$ & $116.0(115.2-116.7)$ & $73.5(72.6-74.5)$ & $71.5(71.0-72.0)$ \\
\hline 2 & $124.9(123.4-126.4)$ & $118.1(117.3-118.9)$ & $75.9(75.0-76.9)$ & $72.3(71.8-72.8)$ \\
\hline 3 & $125.2(123.7-126.7)$ & $118.7(117.9-119.4)$ & $77.2(76.2-78.2)$ & $72.9(72.4-73.3)$ \\
\hline 4 & $126.8(125.3-128.3)$ & $121.2(120.5-122.0)$ & $78.3(77.3-79.2)$ & $74.4(74.0-74.9)$ \\
\hline 5 (highest) & $130.6(129.1-132.1)$ & $124.7(124.0-125.5)$ & $81.3(80.4-82.3)$ & $77.1(76.6-77.6)$ \\
\hline Test of heterogeneity & $P<0.0001$ & $P<0.0001$ & $P<0.0001$ & $P<0.0001$ \\
\hline
\end{tabular}

pressure in both men and women, although the relationship was only statistically significant for SBP in men. Of the macronutrient factors, carbohydrate intake was inversely associated with SBP in men only, saturated fat intake was positively associated with SBP in both sexes, and the $\mathrm{P} / \mathrm{S}$ ratio was inversely associated with blood pressure in both men and women. None of the micronutrients were strongly associated with blood pressure except for calcium intake, which was positively associated with SBP in women.

Men practising vigorous physical exercise had significantly lower blood pressure than men who did not do so, sedentary male workers had higher blood pressure than men who were not working or had more active occupations, and women who had never used oral contraceptives or HRT had higher blood pressure than either former or current users. There were no clear associations between blood pressure and any of the other factors investigated for either sex.

In Table 3 we show the effects of successively adding BMI, selected non-dietary factors, the macronutrient factors and the four micronutrients to the analysis of variance models for blood pressure and diet group in an attempt to account for the variation in age-adjusted blood pressure between the diet groups. Based on the results presented in the Appendix, the non-dietary factors chosen were alcohol intake and vigorous exercise for men and hormone exposure for women. The latter two factors were each categorised as one of 'yes', 'no' or 'unknown' in order to retain all of the observations in the analyses.

BMI accounted for much of the age-adjusted variation in blood pressure between diet groups. After adjusting for BMI, the differences in mean SBP and DBP between the diet groups were considerably reduced, and, except for DBP in women, were no longer statistically significant. Addition of the non-dietary factors further reduced the variation in adjusted mean blood pressures between the diet groups for men but not for women. Along with age and BMI, each of the non-dietary factors was independently associated with blood pressure in these models. Addition of the macronutrient factors further reduced the range in adjusted mean blood pressures for both men and women. Further addition of the micronutrients to the models did not materially alter the results. Comparing the range of adjusted mean values in the models with age, BMI, non-dietary and macronutrient factors with the ranges adjusted for age alone showed that these factors account for more than three-quarters of the variation in blood pressure between the diet groups for men, and for up to two-thirds of the variation for women. For example, the range of age-adjusted mean SBP values in men ( $4.2 \mathrm{mmHg}$ ) was reduced by $83 \%$ to $0.7 \mathrm{~mm} \mathrm{Hg}$ when BMI, alcohol intake, vigorous exercise and the macronutrient factors were added to the model.

\section{Discussion}

We have shown significant differences in the age-adjusted prevalence of self-reported hypertension among meat eaters, fish eaters, vegetarians and vegans for both men and women. Meat eaters had the highest and vegans the lowest prevalence of hypertension, with fish eaters and vegetarians taking intermediate values. Among participants with no self-reported hypertension there were statistically significant variations in age-adjusted mean systolic and diastolic blood pressures between the four diet groups for both men and women, with meat eaters having the highest values and vegans the lowest values. About half of the variation was attributable to differences in body mass index, with non-dietary and macronutrient factors also accounting for some of the variation in mean blood pressure.

The main strength of the study was the large number of observations, especially among vegetarians and vegans. The main limitations of our study were that no standard method of blood pressure measurement was used and that only one measurement was taken. However, the lack of standardisation would not be expected to bias the comparison between diet groups, and the large sample size would help to minimise the effects of the random errors arising from inaccuracies in measurement. In addition, the food-frequency questionnaire is not a very accurate method of assessing nutrient intake $\mathrm{e}^{24}$. This would lead to some misclassification of the nutrient intakes (but not of the diet groups), probably causing the effects of these factors to be underestimated because of regression dilution. It is also possible that prevalent hypertension may have influenced a participant's diet, although the 
Table 3 Mean (95\% confidence interval) systolic and diastolic blood pressures in men and women with no self-reported hypertension by diet group, adjusted for age, body mass index and other relevant factors

\begin{tabular}{|c|c|c|c|c|}
\hline \multirow[b]{2}{*}{ Factors adjusted for } & \multicolumn{2}{|c|}{ Systolic blood pressure } & \multicolumn{2}{|c|}{ Diastolic blood pressure } \\
\hline & Men & Women & Men & Women \\
\hline $\begin{array}{l}\text { Age alone } \\
\text { Meat eaters } \\
\text { Fish eaters } \\
\text { Vegetarians } \\
\text { Vegans } \\
\text { Range of mean values }\left(R^{2}\right)\end{array}$ & $\begin{array}{l}P<0.005 \\
126.6(125.5-127.7) \\
125.3(123.5-127.2) \\
125.5(124.4-126.7) \\
122.4(120.5-124.4) \\
4.2(16.0)\end{array}$ & $\begin{array}{l}P<0.005 \\
120.1(119.6-120.7) \\
119.0(118.1-119.8) \\
120.0(119.4-120.6) \\
117.6(116.1-119.1) \\
2.6(23.1)\end{array}$ & $\begin{array}{l}P<0.005 \\
78.1(77.4-78.8) \\
77.2(75.9-78.4) \\
77.1(76.3-77.8) \\
75.3(74.0-76.5) \\
2.8(3.8)\end{array}$ & $\begin{array}{l}P<0.0001 \\
74.0(73.6-74.3) \\
72.8(72.3-73.3) \\
73.8(73.5-74.2) \\
72.2(71.3-73.2) \\
1.7(11.3)\end{array}$ \\
\hline $\begin{array}{l}\text { Age and BMI } \\
\text { Meat eaters } \\
\text { Fish eaters } \\
\text { Vegetarians } \\
\text { Vegans } \\
\text { Range of mean values }\left(R^{2}\right)\end{array}$ & $\begin{array}{l}P=0.18 \\
126.0(124.9-127.1) \\
125.4(123.6-127.3) \\
125.8(124.7-127.0) \\
123.5(121.6-125.4) \\
2.4(19.9)\end{array}$ & $\begin{array}{l}P=0.08 \\
119.7(119.1-120.2) \\
119.4(118.5-120.2) \\
120.2(119.6-120.7) \\
118.4(116.9-119.8) \\
1.8(26.1)\end{array}$ & $\begin{array}{l}P=0.27 \\
77.6(76.9-78.3) \\
77.3(76.1-78.4) \\
77.3(76.6-78.0) \\
76.1(74.9-77.3) \\
1.4(10.3)\end{array}$ & $\begin{array}{l}P<0.01 \\
73.7(73.3-74.0) \\
73.1(72.6-73.6) \\
74.0(73.6-74.3) \\
72.7(71.8-73.7) \\
1.2(15.1)\end{array}$ \\
\hline $\begin{array}{l}\text { Age, BMI and non-dietary factors* } \\
\text { Meat eaters } \\
\text { Fish eaters } \\
\text { Vegetarians } \\
\text { Vegans } \\
\text { Range of mean values }\left(R^{2}\right)\end{array}$ & $\begin{array}{l}P=0.47 \\
125.6(124.5-126.7) \\
125.4(123.6-127.3) \\
125.9(124.8-127.1) \\
124.2(122.2-126.1) \\
1.8(21.6)\end{array}$ & $\begin{array}{l}P=0.08 \\
119.7(119.2-120.3) \\
119.4(118.6-120.2) \\
120.1(119.6-120.7) \\
118.3(116.8-119.7) \\
1.9(26.4)\end{array}$ & $\begin{array}{l}P=0.59 \\
77.4(76.7-78.1) \\
77.2(76.1-78.4) \\
77.4(76.7-78.1) \\
76.4(75.2-77.7) \\
1.0(11.5)\end{array}$ & $\begin{array}{l}P<0.01 \\
73.7(73.3-74.0) \\
73.1(72.6-73.6) \\
74.0(73.6-74.3) \\
72.7(71.8-73.6) \\
1.2(15.2)\end{array}$ \\
\hline $\begin{array}{l}\text { Age, BMI, non-dietary factors }{ }^{*} \text { and macronutrients } \dagger \\
\text { Meat eaters } \\
\text { Fish eaters } \\
\text { Vegetarians } \\
\text { Vegans } \\
\text { Range of mean values }\left(R^{2}\right)\end{array}$ & $\begin{array}{l}P=0.91 \\
125.3(124.0-126.6) \\
125.5(123.7-127.3) \\
125.9(124.7-127.1) \\
125.2(122.8-127.6) \\
0.7(22.9)\end{array}$ & $\begin{array}{l}P=0.16 \\
119.4(118.8-120.0) \\
119.4(118.6-120.6) \\
120.3(119.7-120.9) \\
119.4(117.8-121.1) \\
0.9(26.8)\end{array}$ & $\begin{array}{l}P=0.96 \\
77.1(76.3-77.9) \\
77.2(76.1-78.4) \\
77.4(76.7-78.2) \\
77.2(75.7-78.8) \\
0.3(12.2)\end{array}$ & $\begin{array}{l}P=0.02 \\
73.5(73.1-73.9) \\
73.1(72.6-73.6) \\
74.0(73.7-74.4) \\
73.2(72.2-74.2) \\
0.9(15.5)\end{array}$ \\
\hline $\begin{array}{l}\text { Age, BMI, non-dietary factors }{ }^{*} \text {, macronutrients } † \text { and micronutrients } \neq \\
\text { Meat eaters } \\
\text { Fish eaters } \\
\text { Vegetarians } \\
\text { Vegans } \\
\text { Range of mean values }\left(R^{2}\right)\end{array}$ & $\begin{array}{l}P=0.66 \\
125.0(123.7-126.3) \\
125.7(123.9-127.5) \\
126.2(124.9-127.4) \\
125.2(122.7-127.6) \\
1.1(23.3)\end{array}$ & $\begin{array}{l}P=0.21 \\
119.4(118.8-120.0) \\
119.4(118.6-120.2) \\
120.3(119.7-120.9) \\
119.5(117.9-121.1) \\
0.9(26.9)\end{array}$ & $\begin{array}{l}P=0.86 \\
77.0(76.1-77.8) \\
77.3(76.1-78.5) \\
77.5(76.7-78.3) \\
77.3(75.8-78.9) \\
0.6(12.7)\end{array}$ & $\begin{array}{l}P=0.02 \\
73.5(73.1-73.9) \\
73.1(72.6-73.6) \\
74.0(73.6-74.4) \\
73.1(72.1-74.2) \\
0.9(15.5)\end{array}$ \\
\hline
\end{tabular}

$P$-values refer to tests of heterogeneity between the diet groups.

$R^{2}$ values denote the percentage of the variance in blood pressure about the mean 'explained' by each model.

*Alcohol intake and vigorous exercise for men, hormone exposure for women.

†Thirds of protein, carbohydrate, total fat, saturated fat and polyunsaturated fat (each as percentage of energy intake), energy, P/S ratio and NSP intake.

$\ddagger$ Thirds of sodium (from food only), potassium, calcium and magnesium intakes. 
analysis of blood pressure measurements was restricted to participants with no evidence of prior hypertension.

Several studies that have investigated the relationships between vegetarian diets and blood pressure have shown a lower blood pressure among vegetarians compared with non-vegetarians ${ }^{7-10}$. Differences in adjusted mean blood pressure between vegetarians and non-vegetarians in these studies ranged from 5 to $10 \mathrm{mmHg}$ systolic and from 2 to $8 \mathrm{mmHg}$ diastolic. Further, two randomised crossover trials in which participants followed a vegetarian diet for six weeks showed reductions in blood pressure of 5$6 \mathrm{mmHg}$ systolic and $2-3 \mathrm{~mm} \mathrm{Hg}$ diastolic compared with their normal meat-based diet ${ }^{25,26}$. In our study, the differences in age-adjusted mean blood pressure between vegetarians and meat-eaters were much lower than this, being no more than about $1 \mathrm{~mm} \mathrm{Hg}$ systolic or diastolic (Table 3). However, our vegan group, who do not eat any animal products, had lower blood pressure than each of the other diet groups including the vegetarians, who eat dairy products and/or eggs. Beilin and Burke identified vegetarian diets characterised by a relatively low intake of saturated fat, a high $\mathrm{P} / \mathrm{S}$ ratio and a high intake of dietary fibre as being most clearly associated with a reduction in blood pressure ${ }^{27}$. The nutrient intake of the vegans in our study best matches these characteristics (Table 1).

In our study, vegetarian women had higher ageadjusted mean blood pressure than did fish eaters. The differences were much less than those found in a comparison of fish-eating and vegetarian Bantu villagers in Tanzania ${ }^{28}$, although the diets of Bantu villagers and participants in our study are very different. However, vegans, who do not eat any animal products, had the lowest age-adjusted mean blood pressure of the four diet groups. Therefore, an increased dietary intake of omega-3 fatty acids through the consumption of fish may not be necessary for controlling blood pressure, as others have recommended $^{29}$. It is also interesting to note that the vegans had only about half the calcium intake of the other diet groups. An inadequate calcium intake has sometimes been associated with higher blood pressures ${ }^{30}$, but others have suggested that increasing calcium intake will be generally ineffective in reducing blood pressure ${ }^{31}$. However, the vegans did have the lowest intakes of alcohol and sodium from food, and, importantly, the lowest age-adjusted body mass index, factors likely to lead to a reduction in blood pressure ${ }^{4,5}$. Indeed, 500 participants in a 12-day intervention study of a low-fat vegan diet, combined with moderate exercise and stress management, experienced a significant $6 \%$ reduction in blood pressure ${ }^{32}$. The fact that sodium intake from food was not associated with blood pressure in our study may be because the food-frequency questionnaire was not designed to provide an accurate estimate of sodium consumption, and our results should not be interpreted as evidence against the role of this nutrient in hypertension management.
Our data show that much of the difference in blood pressure between the diet groups may be explained by differences in body mass index. After adjusting for age and body mass index, the differences in mean blood pressure between vegetarians and meat eaters were each less than $0.5 \mathrm{~mm} \mathrm{Hg}$ for men and women respectively (Table 3). These differences are much less than the differences of 5$6 \mathrm{mmHg}$ systolic and 3-4 mmHg diastolic after adjustment for obesity found in a comparison of lacto-ovo-vegetarian Seventh-day Adventists and Mormon meat eaters ${ }^{10}$. Additional adjustment for non-dietary and macronutrient factors further reduced the variation in mean blood pressure, suggesting that dietary factors account for some of the differences in blood pressure between the diet groups. Precisely which dietary factors are responsible is difficult to determine, as has been noted previously ${ }^{27,33}$. In all probability a combination of factors is important, although other non-dietary factors not considered here might also play a role.

In summary, in a free-living Western population, nonmeat eaters, especially vegans, had a lower age-adjusted prevalence of self-reported hypertension and a lower blood pressure than did meat eaters. The differences were largely attributable to the lower body mass index of the non-meat eaters. Although relatively small, the differences observed might be expected to confer worthwhile reductions in the risks of stroke and coronary heart disease among vegans and persons with a low intake of animal products. Indeed, a collaborative analysis of mortality in vegetarians and non-vegetarians showed that vegetarians had a significant $24 \%$ lower death rate from ischaemic heart disease and a non-significant $7 \%$ lower death rate from cerebrovascular disease compared with non-vegetarians ${ }^{34}$.

\section{Acknowledgements}

We thank all the participants in EPIC-Oxford and all the scientists and clerical staff who have worked on this study. EPIC-Oxford is supported by Cancer Research UK, the Europe Against Cancer Programme of the Commission of the European Community and the Medical Research Council.

\section{References}

1 Stamler J, Stamler R, Neaton JD. Blood pressure, systolic and diastolic, and cardiovascular risks: US population data. Arch. Intern. Med. 1993; 153: 598-615.

2 van den Hoogen PC, Feskens EJ, Nagelkerke NJ, et al. The relation between blood pressure and mortality due to coronary heart disease among men in different parts of the world. N. Engl. J. Med. 2000; 342: 1-8.

3 MacMahon S, Peto R, Cutler J, et al. Blood pressure, stroke, and coronary heart disease. 1. Prolonged differences in blood pressure: prospective observational studies corrected for the regression dilution bias. Lancet 1990; 335: 765-74.

4 Elliott P, Marmot M, Dyer A, et al. The INTERSALT study: 
main results, conclusions, and some implications. Clin. Exp. Hypertens. - Part A, Theory \& Practice 1989; 11(5-6): 1025-34.

5 Elliott P, Stamler J, Nichols R, et al. INTERSALT revisited: further analyses of 24-hour sodium excretion and blood pressure within and across populations. Br. Med. J. 1996; 312: $1249-53$.

6 Sacks FM, Stevkey LP, Vollmer WM, et al. Effects on blood pressure of reduced dietary sodium and the Dietary Approaches to Stop Hypertension (DASH) diet. N. Engl. J. Med. 2001; 344: 3-10.

7 Sacks FM, Rosner B, Kass EH. Blood pressure in vegetarians. Am. J. Epidemiol. 1974; 100: 390-8.

8 Armstrong B, Van Merwyk AJ, Coates H. Blood pressure in Seventh-Day Adventist vegetarians. Am. J. Epidemiol. 1977; 105: 444-9.

9 Armstrong B, Clarke H, Martin C, et al. Urinary sodium and blood pressure in vegetarians. Am. J. Clin. Nutr. 1979; 32: 2472-6.

10 Rouse IL, Armstrong BK, Beilin LJ. The relationship of blood pressure to diet and lifestyle in two religious populations. J. Hypertens. 1983; 1: 65-71.

11 Holland B, Brown J, Buss DH. Fish and Fish Products. Third Supplement to McCance and Widdowson's The Composition of Foods, 5th ed. Cambridge: Royal Society of Chemistry, 1993.

12 Holland B, Unwin ID, Buss DH. Cereals and Cereal Products. Third Supplement to McCance and Widdowson's The Composition of Foods, 4th ed. Cambridge: Royal Society of Chemistry, 1988.

13 Holland B, Unwin ID, Buss DH. Milk Products and Eggs. Fourth Supplement to McCance and Widdowson's The Composition of Foods, 4th ed. Cambridge: Royal Society of Chemistry, 1989.

14 Holland B, Unwin ID, Buss DH. Vegetables, Herbs and Spices. Fifth Supplement to McCance and Widdowson's The Composition of Foods, 4th ed. Cambridge: Royal Society of Chemistry, 1991.

15 Holland B, Unwin ID, Buss DH. Fruit and Nuts. First Supplement to McCance and Widdowson's The Composition of Foods, 5th ed. Cambridge: Royal Society of Chemistry, 1992.

16 Holland B, Welch AA, Buss DH. Vegetable Dishes. Second Supplement to McCance and Widdowson's The Composition of Foods, 5th ed. Cambridge: Royal Society of Chemistry, 1992.

17 Holland B, Welch AA, Unwin ID, et al. McCance and Widdowson's The Composition of Foods, 5th ed. Cambridge: Royal Society of Chemistry, 1991.

18 Chan W, Brown J, Buss DH. Miscellaneous Foods. Fourth Supplement to McCance and Widdowson's The Composition of Foods, 5th ed. Cambridge: Royal Society of Chemistry, 1994.
19 Chan W, Brown J, Church SM, et al. Meat Products and Dishes. Sixth Supplement to McCance and Widdowson's The Composition of Foods, 5th ed. Cambridge: Royal Society of Chemistry, 1996.

20 Chan W, Brown J, Lee SM, et al. Meat, Poultry and Game. Fifth Supplement to McCance and Widdowson's The Composition of Foods, 5th ed. Cambridge: Royal Society of Chemistry, 1995.

21 Bingham SA, Gill C, Welch A, et al. Validation of dietary assessment methods in the UK arm of EPIC using weighed records, and 24-hour urinary nitrogen and potassium and serum vitamin $\mathrm{C}$ and carotenoids as biomarkers. Int. J. Epidemiol. 1997; 26(Suppl. 1): 137S-51S.

22 Spencer EA, Appleby PN, Davey GK, Key TJ. Validity of selfreported height and weight in 4808 EPIC-Oxford participants. Public Health Nutr. 2002; 5: 561-5.

23 Stata Corporation. Stata Statistical Software: Release 7.0. College Station, TX: StataCorp, 2001.

24 Day N, McKeown N, Wong M, et al. Epidemiological assessment of diet: a comparison of a 7-day diary with a food frequency questionnaire using urinary markers of nitrogen, potassium and sodium. Int. J. Epidemiol. 2001; 30: 309-17.

25 Rouse IL, Beilin LJ, Armstrong BK, et al. Blood pressure lowering effect of a vegetarian diet: a controlled trial in normotensive subjects. Lancet 1983; 1: 5-10.

26 Margetts BM, Beilin LJ, Vandongen R, et al. Vegetarian diet in mild hypertension: a randomised controlled trial. $\mathrm{Br}$. Med. J. 1986; 293: 1468-71.

27 Beilin LJ, Burke V. Vegetarian diet components, protein and blood pressure: which nutrients are important? Clin. Exp. Pharmacol. Physiol. 1995; 22: 195-8.

28 Pauletto P, Puato M, Caroli MG, et al. Blood pressure and atherogenic lipoprotein profiles of fish-diet and vegetarian villagers in Tanzania: the Lugalawa study. Lancet 1996; 348 : $784-8$.

29 Mori TA, Beilin LJ. Long-chain omega 3 fatty acids, blood lipids and cardiovascular risk reduction. Curr. Opin. Lipidol. 2001; 12: 11-17.

30 McCarron DA, Reusser ME. Are low intakes of calcium and potassium important causes of cardiovascular disease? Am. J. Hypertens. 2001; 14: 206S-12S.

31 Silverberg DS. Non-pharmacological treatment of hypertension. J. Hypertens. 1990; 8: 21S-6S.

32 McDougall J, Litzau K, Haver E, et al. Rapid reduction of serum cholesterol and blood pressure by a twelve-day, very low fat, strictly vegetarian diet. J. Am. Coll. Nutr. 1995; 14: 491-6.

33 Beilin LJ. Vegetarian and other complex diets, fats, fiber, and hypertension. Am. J. Clin. Nutr. 1994; 59: 1130S-5S.

34 Key TJ, Fraser GE, Thorogood M, et al. Mortality in vegetarians and nonvegetarians: detailed findings from a collaborative analysis of 5 prospective studies. Am. J. Clin. Nutr. 1999; 70(Suppl.): 516S-24S.

\section{Appendix - Mean (95\% confidence interval) systolic and diastolic blood pressures in men and women with no self-reported hypertension by alcohol and nutrient intakes and other relevant factors, each adjusted for age and body mass index}

\begin{tabular}{|c|c|c|c|c|}
\hline \multirow[b]{2}{*}{ Factor } & \multicolumn{2}{|c|}{ Systolic blood pressure $(\mathrm{mmHg})$} & \multicolumn{2}{|c|}{ Diastolic blood pressure $(\mathrm{mmHg})$} \\
\hline & Men & Women & Men & Women \\
\hline Alcohol (g ethanol day ${ }^{-1}$ ) & $P<0.0005$ & $P=0.54$ & $P<0.005$ & $P=0.24$ \\
\hline$<1$ & $122.6(121.0-124.3)$ & $120.0(119.2-120.7)$ & $75.7(74.6-76.7)$ & $73.5(73.0-74.0)$ \\
\hline $1-9$ & $125.6(124.5-126.6)$ & $119.5(119.0-120.0)$ & $77.3(76.7-78.0)$ & $73.5(73.2-73.8)$ \\
\hline $10-19$ & $125.5(124.1-126.9)$ & $120.0(119.2-120.7)$ & $77.3(76.4-78.2)$ & 73.7 (73.2-74.2) \\
\hline $20+$ & $127.6(126.2-129.1)$ & $120.2(118.9-121.4)$ & $78.3(77.4-79.2)$ & $74.3(73.6-75.1)$ \\
\hline
\end{tabular}


Appendix Continued

\begin{tabular}{|c|c|c|c|c|}
\hline \multirow[b]{2}{*}{ Factor } & \multicolumn{2}{|c|}{ Systolic blood pressure (mmHg) } & \multicolumn{2}{|c|}{ Diastolic blood pressure $(\mathrm{mmHg})$} \\
\hline & Men & Women & Men & Women \\
\hline Energy & $P<0.01$ & $P=0.06$ & $P=0.09$ & $P=0.08$ \\
\hline Bottom third & $124.0(122.9-125.2)$ & $119.2(118.6-119.8)$ & $76.7(76.0-77.4)$ & $73.3(72.9-73.7)$ \\
\hline Middle third & $126.4(125.2-127.5)$ & $119.8(119.2-120.3)$ & $77.9(77.1-78.6)$ & $73.7(73.4-74.1)$ \\
\hline Top third & $126.2(125.1-127.4)$ & $120.2(119.6-120.8)$ & $77.2(76.4-77.9)$ & $73.9(73.5-74.2)$ \\
\hline Protein (\% energy) & $P=0.18$ & $P=0.33$ & $P=0.52$ & $P=0.65$ \\
\hline Bottom third & $125.5(124.4-126.7)$ & $119.6(119.0-120.2)$ & $77.0(76.2-77.7)$ & $73.6(73.3-74.0)$ \\
\hline Middle third & $126.3(125.2-127.4)$ & $120.1(119.5-120.7)$ & $77.6(76.8-78.3)$ & $73.7(73.4-74.1)$ \\
\hline Top third & $124.7(123.6-125.9)$ & $119.5(118.9-120.1)$ & $77.2(76.4-77.9)$ & $73.5(73.1-73.9)$ \\
\hline Carbohydrate (\% energy) & $P=0.01$ & $P=0.42$ & $P=0.16$ & $P=0.31$ \\
\hline Bottom third & $126.3(125.2-127.5)$ & $119.9(119.3-120.5)$ & $77.6(76.8-78.3)$ & $73.9(73.5-74.2)$ \\
\hline Middle third & $126.2(125.0-127.3)$ & $119.9(119.3-120.5)$ & $77.5(76.8-78.2)$ & $73.6(73.2-73.9)$ \\
\hline Top third & $124.1(122.9-125.2)$ & $119.4(118.8-120.0)$ & $76.7(75.9-77.4)$ & $73.5(73.1-73.8)$ \\
\hline Total fat (\% energy) & $P=0.99$ & $P=0.42$ & $P=0.87$ & $P=0.75$ \\
\hline Bottom third & $125.6(124.4-126.7)$ & $119.7(119.1-120.3)$ & $77.1(76.4-77.9)$ & $73.7(73.3-74.0)$ \\
\hline Middle third & $125.6(124.4-126.7)$ & $119.5(118.9-120.1)$ & $77.4(76.7-78.1)$ & $73.5(73.1-73.9)$ \\
\hline Top third & $125.5(124.3-126.6)$ & $120.0(119.4-120.6)$ & $77.2(76.5-78.0)$ & $73.7(73.3-74.1)$ \\
\hline Saturated fat (\% energy) & $P=0.03$ & $P<0.005$ & $P=0.11$ & $P=0.06$ \\
\hline Bottom third & $124.4(123.2-125.5)$ & $119.2(118.6-119.8)$ & $76.6(75.9-77.3)$ & $73.5(73.1-73.8)$ \\
\hline Middle third & $125.5(124.4-126.7)$ & $119.3(118.8-119.9)$ & $77.5(76.8-78.2)$ & $73.4(73.1-73.8)$ \\
\hline Top third & $126.7(125.5-127.8)$ & $120.6(120.1-121.2)$ & $77.6(76.9-78.4)$ & $74.0(73.6-74.4)$ \\
\hline Polyunsaturated fat (\% energy) & $P=0.06$ & $P=0.94$ & $P=0.27$ & $P=0.59$ \\
\hline Bottom third & $126.6(125.5-127.8)$ & $119.8(119.2-120.4)$ & $77.6(76.9-78.4)$ & $73.8(73.4-74.1)$ \\
\hline Middle third & $124.7(123.6-125.9)$ & $119.7(119.2-120.3)$ & $76.8(76.1-77.5)$ & $73.6(73.3-74.0)$ \\
\hline Top third & $125.2(124.1-126.4)$ & $119.7(119.1-120.2)$ & $77.3(76.6-78.0)$ & $73.5(73.1-73.9)$ \\
\hline $\mathrm{P} / \mathrm{S}$ ratio & $P=0.01$ & $P<0.005$ & $P=0.07$ & $P=0.02$ \\
\hline Bottom third & $126.9(125.8-128.1)$ & $120.2(119.6-120.8)$ & $77.8(77.1-78.6)$ & $73.8(73.5-74.2)$ \\
\hline Middle third & $125.1(123.9-126.2)$ & $120.1(119.6-120.7)$ & $77.3(76.6-78.0)$ & $73.9(73.5-74.2)$ \\
\hline Top third & $124.6(123.4-125.8)$ & $118.8(118.2-119.4)$ & $76.6(75.9-77.4)$ & $73.2(72.8-73.6)$ \\
\hline NSP & $P=0.77$ & $P=0.34$ & $P=0.23$ & $P=0.44$ \\
\hline Bottom third & $125.9(124.7-127.0)$ & $120.1(119.5-120.7)$ & $77.7(76.9-78.4)$ & $73.8(73.4-74.2)$ \\
\hline Middle third & $125.3(124.2-126.5)$ & $119.5(118.9-120.1)$ & $77.3(76.5-78.0)$ & $73.5(73.1-73.9)$ \\
\hline Top third & $125.4(124.2-126.5)$ & $119.6(119.0-120.2)$ & $76.8(76.0-77.5)$ & $73.6(73.2-73.9)$ \\
\hline Sodium (from food only) & $P=0.14$ & $P=0.32$ & $P=0.69$ & $P=0.19$ \\
\hline Bottom third & $125.0(123.8-126.1)$ & $119.5(118.9-120.0)$ & $77.4(76.6-78.1)$ & $73.4(73.0-73.7)$ \\
\hline Middle third & $125.1(124.0-126.3)$ & $119.7(119.1-120.3)$ & $77.0(76.2-77.7)$ & 73.7 (73.3-74.0) \\
\hline Top third & $126.5(125.3-127.6)$ & $120.1(119.5-120.7)$ & $77.4(76.6-78.1)$ & $73.8(73.5-74.2)$ \\
\hline Potassium & $P=0.47$ & $P=0.06$ & $P=0.70$ & $P=0.17$ \\
\hline Bottom third & $125.0(123.8-126.1)$ & $119.9(119.3-120.5)$ & 77.4 (76.7-78.2) & $73.5(73.2-73.9$ \\
\hline Middle third & 125.6 (124.4-126.7) & $119.2(118.6-119.8)$ & $77.0(76.3-77.7)$ & $73.4(73.1-73.8)$ \\
\hline Top third & $126.0(124.9-127.2)$ & $120.2(119.6-120.7)$ & $77.3(76.6-78.0)$ & $73.9(73.5-74.3)$ \\
\hline Calcium & $P=0.30$ & $P=0.02$ & $P=0.49$ & $P=0.13$ \\
\hline Bottom third & $124.9(123.7-126.0)$ & $119.1(118.5-119.7)$ & $76.9(76.2-77.6)$ & $73.3(72.9-73.7)$ \\
\hline Middle third & $126.1(125.0-127.3)$ & $119.9(119.3-120.5)$ & $77.5(76.8-78.3)$ & $73.7(73.4-74.1)$ \\
\hline Top third & $125.6(124.4-126.7)$ & $120.3(119.7-120.9)$ & $77.3(76.6-78.1)$ & 73.8 (73.5-74.2) \\
\hline Magnesium & $P=0.89$ & $P=0.97$ & $P=0.19$ & $P=0.50$ \\
\hline Bottom third & $125.7(124.5-126.8)$ & $119.7(119.1-120.3)$ & $77.8(77.1-78.5)$ & $73.5(73.1-73.8)$ \\
\hline Middle third & $125.3(124.1-126.4)$ & $119.7(119.1-120.3)$ & $77.1(76.3-77.8)$ & $73.6(73.3-74.0)$ \\
\hline Top third & $125.6(124.5-126.8)$ & $119.8(119.2-120.4)$ & $76.9(76.1-77.6)$ & $73.8(73.4-74.1)$ \\
\hline Salt added while cooking & $P=0.04$ & $P=0.08$ & $P=0.06$ & $P=0.11$ \\
\hline Rarely or never & $124.7(123.7-125.6)$ & $119.5(119.0-120.0)$ & $76.7(76.1-77.4)$ & $73.4(73.1-73.7)$ \\
\hline Sometimes & $126.8(125.2-128.4)$ & $119.4(118.6-120.2)$ & $78.1(77.1-79.1)$ & $73.5(73.0-74.0)$ \\
\hline Usually or always & $126.0(124.9-127.1)$ & $120.3(119.7-120.8)$ & 77.5 (76.8-78.2) & $73.9(73.6-74.3$ \\
\hline Salt added at the table & $P=0.32$ & $P=0.37$ & $P=0.09$ & $P=0.73$ \\
\hline Rarely or never & $125.4(124.5-126.2)$ & $119.5(119.1-120.0)$ & $76.9(76.3-77.4)$ & $73.6(73.3-73.8)$ \\
\hline Sometimes & $125.0(123.4-126.5)$ & $120.1(119.4-120.8)$ & $77.8(76.8-78.8)$ & $73.8(73.3-74.2)$ \\
\hline Usually or always & $126.5(125.0-127.9)$ & $120.0(119.1-120.8)$ & 77.9 (77.0-78.8) & 73.7 (73.2-74.2) \\
\hline Physical activity at work & $P=0.06$ & $P=0.93$ & $P=0.03$ & $P=0.37$ \\
\hline Not working & $125.0(123.6-126.4)$ & $119.7(119.0-120.3)$ & $76.9(76.0-77.8)$ & $73.5(73.1-73.9)$ \\
\hline Sedentary & $126.7(125.6-127.8)$ & $119.8(119.2-120.4)$ & $78.0(77.3-78.8)$ & $73.9(73.5-74.2)$ \\
\hline Active & $124.9(123.6-126.2)$ & $119.8(119.2-120.4)$ & $76.7(75.9-77.5)$ & $73.6(73.2-73.9)$ \\
\hline Vigorous exercise & $P<0.0001$ & $P=0.22$ & $P<0.001$ & $P=0.59$ \\
\hline Yes & $124.7(123.9-125.4)$ & $119.5(119.1-119.9)$ & $76.8(76.3-77.3)$ & $73.6(73.3-73.8)$ \\
\hline No & $128.2(126.8-129.6)$ & $120.0(119.4-120.7)$ & $78.6(77.8-79.5)$ & $73.7(73.3-74.1)$ \\
\hline Parity & & $P=0.14$ & & $P=0.06$ \\
\hline None & - & $120.0(119.4-120.6)$ & - & $74.0(73.6-74.4)$ \\
\hline $1-2$ & - & $119.8(119.3-120.3)$ & - & $73.4(73.1-73.8)$ \\
\hline 3 or more & - & $119.0(118.1-119.8)$ & - & $73.3(72.8-73.8)$ \\
\hline
\end{tabular}


Appendix Continued

\begin{tabular}{|c|c|c|c|c|}
\hline \multirow[b]{2}{*}{ Factor } & \multicolumn{2}{|c|}{ Systolic blood pressure (mmHg) } & \multicolumn{2}{|c|}{ Diastolic blood pressure $(\mathrm{mmHg})$} \\
\hline & Men & Women & Men & Women \\
\hline Hormone exposure* & & $P<0.0001$ & & $P=0.02$ \\
\hline Never & _ & $121.5(120.7-122.3)$ & _- & $74.2(73.7-74.7)$ \\
\hline Former & - & $119.0(118.6-119.5)$ & - & $73.3(73.1-73.6)$ \\
\hline Current & _ & $119.8(119.1-120.6)$ & _- & $73.8(73.3-74.3)$ \\
\hline Smoked cigarettes in $24 \mathrm{~h}$ prior to BP measurement & $P=0.87$ & $P=0.16$ & $P=0.13$ & $P=0.49$ \\
\hline Yes & $125.3(122.5-128.0)$ & $118.8(117.5-120.1)$ & $75.9(74.1-77.7)$ & $73.4(72.5-74.2)$ \\
\hline No & $125.5(124.8-126.2)$ & $119.8(119.4-120.2)$ & $77.3(76.9-77.8)$ & $73.7(73.4-73.9)$ \\
\hline Took medicationt prior to BP measurement & $P=0.39$ & $P=0.48$ & $P=0.74$ & $P=0.82$ \\
\hline Yes & $125.5(124.4-126.5)$ & $120.1(119.7-120.6)$ & $77.2(76.5-77.9)$ & $73.8(73.5-74.1)$ \\
\hline No & $126.1(125.1-127.1)$ & $119.9(119.2-120.5)$ & $77.4(76.7-78.0)$ & $73.9(73.5-74.3)$ \\
\hline Receiving long-term treatment for illness & $P=0.38$ & $P=0.13$ & $P=0.70$ & $P=0.20$ \\
\hline Yes & $125.0(123.6-126.4)$ & $119.3(118.6-119.9)$ & $77.4(76.5-78.3)$ & $73.4(73.0-73.8)$ \\
\hline No & $125.7(125.0-126.4)$ & $119.9(119.5-120.3)$ & $77.2(76.7-77.7)$ & $73.7(73.4-73.9)$ \\
\hline
\end{tabular}

$P$-values refer to tests of heterogeneity between the categories.

BP - blood pressure.

*Oral contraceptives or hormone replacement therapy.

†Includes prescription medicines, over-the-counter medicines and nutritional supplements. 